\title{
水稻温敏显性核不育基因的遗传分析 和分子标记定位
}

\author{
李仕贵 (4) 周开达 朱立煌 (4)
}

( 四川农业大学水稻研究所, 温江 611130; 4中国科学院遗传研究所, 北京 100101)

摘要 温敏核不育材料 8987 , 在 $24^{\circ} \mathrm{C}$ 以下完成雄性不育, $27^{\circ} \mathrm{C}$ 以上恢复可育. 利用该材料与 3 个可育品种杂交, 并对 $\mathrm{F}_{1}$ 和 $\mathrm{F}_{2}$ 群体进行花粉育性观察和遗传分析, 确认 8987 的不育特性受一 对显性基因控制. 以 $\mathrm{F}_{2}$ 群体 (8987 × 地谷) 为基础, 应用 RFLP 和微卫星标记结合群分法, 发现 第 6 染色体的 RFLP 标记 C235 和微卫星标记 RM50 与显性核不育基因连锁; 进一步将该基因 定位于第 6 染色体具体位置. 由于该基因是首次定位, 暂定名为 TMS.

\section{关键词 温敏核不育 限制性片段长度多态性(RFLP) 微卫星标记 基因定位}

雄性不育是植物界一种普遍存在的现象, 迄今已在 43 个科 162 个属 617 种植物中发现了 这一现象, 其中包括水稻、小麦、玉米、油菜和棉花等重要农作物 ${ }^{[1]}$. 水稻雄性不育的最早报道 出自本世纪 20 年代, 自 60 年代以来, 国内外相继发现了许多不同遗传类型的水稻雄性不育材 料, 绝大多数为隐性核不育, 包括目前杂交水稻上应用的核质互作不育、光温敏隐性核不育以 及用于水稻轮回选择的单基因隐性核不育，极少数为显性核不育 ${ }^{[2]}$. 迄今仅报道了 2 份显性 核不育材料, 即萍乡显性核不育 ${ }^{[3]}$ 和本文将研究的温敏显性核不育. 对于水稻雄性不育基因 的定位, 70 80 年代主要借助水稻三体和性状标记分析判明不育基因所在的染色体, 如隐性

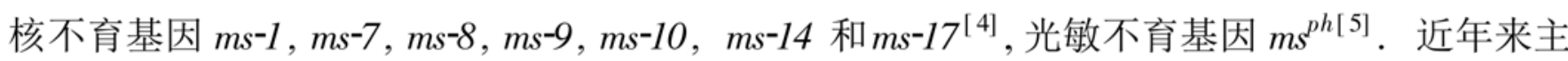
要应用分子标记构建分子遗传连锁图的方法进行定位, 如光敏不育基因 $P M s 1$ 和 $P M s 2^{[6]}$, 温敏 不育基因 $T M s 12^{[7]}$. 本研究利用 RFLP 和微卫星标记结合 $\mathrm{F}_{2}$ 群分法, 对来源于四川农业大学 水稻研究所的中间材料 8987 的温敏核不育基因进行遗传分析和分子标记定位, 以期寻找与该 温敏显性核不育基因紧密连锁的分子标记在水稻遗传育种中进行辅助选择.

\section{1 材料与方法}

（）供试材料和育性调查. 1989 年在 3304/ 明恢 63 的 $\mathrm{F}_{5}$ 代发现 1 株水稻雄性不育株, 具有温敏不育特性, 定名为 $8987^{[8]}$. 1995 年用它与育性正常的水稻品种地谷、297B 和测 64 配 制杂交组合 $F_{1}$ 和 $F_{2}$. 1996 年夏季, 采用分期播种的方法( 从 4 月 15 日开始, 间隔 $10 \mathrm{~d}$, 分 3 期 播种), 每期亲本各 2 行, $F_{1}$ 各 1 行, 每行 10 株, 种植于四川农业大学水稻研究所试验场, 田块 土壤肥力均匀. 在抽穗期, 用 I-IK 对亲本 8987 和全部 $\mathrm{F}_{1}$ 代进行花粉镜检, 并观察花药形态和 散粉情况. 1996 年冬在海南继续将亲本和 $\mathrm{F}_{1}$ 代分期播种, 同时种植各组合 $\mathrm{F}_{2}$ 群体, 每个组合 250 株左右. 观察亲本和 $\mathrm{F}_{1}$ 代的花粉育性, 并根据亲本和 $\mathrm{F}_{1}$ 的育性表现, 对 $\mathrm{F}_{2}$ 代单株进行育 性分类调查.

（）近等基因池的构建和 RFLP 分析. 在育性观察的基础上, 从 $\mathrm{F}_{2}$ 群体 $(8987 \times$ 地谷 $)$ 中, 分别随机选取 10 个不育和可育单株, 每个单株各取等量叶片, 再将不育和可育单株的叶片 分别混合提取 DNA, 形成不育和可育 DNA 池 ${ }^{[9]}$. 同时提取 $F_{2}$ 群体单株总 DNA, 用于限制性酶 
解、Southern 转移和分子杂交, 其方法主要参照文献[ 10] 的步骤进行. 采用 8 种限制性内切酶: $E c o$ R iv, $B a m H$ iv, $H i n d$ 园 $S c a$ iv, $E c o$ R (九) $B g l$ 司, Dra iv和 $X b a$ iv. 探针由美国 Cornell 大学 Tanksley 实验室和日本 RGP 馈赠.

（）微卫星 DNA 标记(SSLR) 分析. 按照 Chen 等人 ${ }^{[1]}$ 提供的微卫星序列合成引物. PCR 反应体系参照 Panaud 等人 ${ }^{[12]}$ 的方法进行. 反应产物在 $4 \%$ 琼脂糖凝胶中电泳, 经溴化乙 锭染色后在紫外灯下观察拍照.

( ) 遗传作图. 用 MAPMAKER 软件对分离群体的抗性和标记的分离数据进行连锁分 析, 利用 Kosambi 函数将重组率转化为遗传图距 $(\mathrm{cM})^{[13]}$.

\section{2 结果分析}

\subsection{7 不育基因的遗传分析}

1996 年 7 月 12 日 8 月 17 日, 在温江自然条件下每隔 5 $6 \mathrm{~d}$ 对 8987 亲本及其 $\mathrm{F}_{1}$ 代进行 1 次花粉育性鉴定 (表 1), 结果表明, 花粉育性变化较大, 7 月 12 日和 8 月 2 日, 8987 和其 $\mathrm{F}_{1}$ 代 花粉完全败育, 可育花粉率 0 0.07\%.8 月 17 日, 花粉育性基本正常, 可育花粉率为 78. 35\% $89.21 \%$, 其余 5 次花粉镜检结果表明, 育性出现较大波动, 但未发现组合特异性. 根据 6 月 28 日 8 月 20 日的日平均温度与 8987 及其 $\mathrm{F}_{1}$ 代的育性变化分析, 育性受花粉镜检前 14 $16 \mathrm{~d}$ 的日平均温度影响, 属于典型温敏型败育. 在温江 7 8 月份的光温条件下, 8987 及其 $\mathrm{F}_{1}$ 的温 度敏感期应在花粉母细胞形成期至花粉单核期, 其临界温度大约为 $24 \sim 27{ }^{\circ} \mathrm{C}$. 如果在温度敏 感期连续 $3 \mathrm{~d} 24{ }^{\circ} \mathrm{C}$ 以下, 8987 和 $\mathrm{F}_{1}$ 表现完全不育, $27^{\circ} \mathrm{C}$ 以上育性基本正常, $24 \sim 27{ }^{\circ} \mathrm{C}$ 之间呈不 同程度的败育, 其败育期花药瘦小, 白色水渍状, 花粉败育类型以典败为主.

表 18987 亲本及其 $F_{1}$ 代在四川温江的花粉育性表现

\begin{tabular}{cccccc}
\hline \multirow{2}{*}{ 日期(月/日) } & \multicolumn{5}{c}{ 花粉育性/\% } \\
\cline { 2 - 5 } & 亲本 8987 & $\mathrm{~F}_{1}$ 代 $(8987 \times$ 地谷 $)$ & $\mathrm{F}_{1}$ 代 $(8987 \times 297 \mathrm{~B})$ & $\mathrm{F}_{1}$ 代 $(8987 \times$ 测 64$)$ & 敏感期温度/ ${ }^{\circ} \mathrm{C}$ \\
\hline $7 / 12$ & - & 0 & 0 & - & $22.7 \pm 0.9$ \\
$7 / 17$ & - & $11.81 \pm 4.76$ & $12.67 \pm 5.32$ & - & $25.8 \pm 0.8$ \\
$7 / 22$ & - & $2.65 \pm 0.87$ & $3.34 \pm 0.79$ & - & $24.8 \pm 1.1$ \\
$7 / 28$ & - & $1.37 \pm 0.53$ & $1.23 \pm 0.48$ & $0.86 \pm 0.31$ & $24.5 \pm 0.6$ \\
$8 / 2$ & 0 & 0 & 0.02 & 0.05 & $23.9 \pm 0.3$ \\
$8 / 8$ & $27.34 \pm 13.26$ & $14.97 \pm 8.63$ & $36.68 \pm 19.76$ & $8.39 \pm 6.37$ & $26.0 \pm 1.6$ \\
$8 / 12$ & $1.41 \pm 0.46$ & $1.52 \pm 0.63$ & $2.73 \pm 0.88$ & $2.04 \pm 0.82$ & $24.7 \pm 1.2$ \\
$8 / 17$ & $78.35 \pm 12.31$ & - & $84.56 \pm 7.21$ & $87.33 \pm 3.36$ & $27.3 \pm 0.4$ \\
\hline
\end{tabular}

1997 年海南陵水, 3 月 5 日 3 月 14 日, 日平均温度在 $24{ }^{\circ} \mathrm{C}$ 以下, 亲本 8987 和 $\mathrm{F}_{1}$ 代花粉 稳定败育, 另一亲本地谷、297B 和测 64 育性正常, 可排除低温导致的生理不育. 根据 8987 和 $\mathrm{F}_{1}$ 代育性表现对 3 月 5 日 3 月 14 日抽穗的 $\mathrm{F}_{2}$ 代单株进行育性分类, 3 个组合的 $\mathrm{F}_{2}$ 代群体 的不育和可育单株比例经 $x^{2}$ 测验符合 3: 1 (表 2), 表明 8987 的育性受 1 对显性基因控制. 3 月 15 日以后抽穗的 $8987, \mathrm{~F}_{1}$ 群体和 $\mathrm{F}_{2}$ 单株随着温度的不断增高, 育性波动直至恢复正常, 进一 步说明 8987 的育性受温度的控制, 与抽穗期无关. 
表 $2 \quad F_{2}$ 代植株的育性表现

\begin{tabular}{ccccccc}
\hline 组合 & 观察植株数 & 不育株 & 可育株 & 期望比 & $x^{2}$ & $P_{0.05,0.01}$ \\
\hline $\mathrm{F}_{2}(8987 \times$ 地谷 $)$ & 151 & 109 & 42 & $3: 1$ & 0.6380 & $3.84,6.63$ \\
$\mathrm{~F}_{2}(8987 \times 297 \mathrm{~B})$ & 146 & 101 & 45 & $3: 1$ & 2.6393 & $3.84,6.63$ \\
$\mathrm{~F}_{2}(8987 \times$ 测 64$)$ & 114 & 76 & 38 & $3: 1$ & 4.2222 & $3.84,6.63$ \\
\hline
\end{tabular}

2.2 亲本多态性检测和温敏不育基因的连锁分子标记篮选

用 8 种酶配合 138 个 RFLP 探针和 59 个微卫星标记检测亲 本, 揭示亲本多态性的探针和标记共 67 个, 多态性表现频率为 $34.01 \%$ 。应用上述 67 个亲本多态性探针和微卫星标记检测温敏 显性核不育基因的 2 对近等基因池, 其中位于第 6 染色体的 RFLP 探针 C235 和微卫星标记 RM50 在不育和可育近等基因池中表现 多态 (图 1), 暗示温敏显性核不育基因位于第 6 染色体，与 C235 和 RM50 连锁. 为了进一步确定温敏显性核不育基因在第 6 染色 体的准确位点, 用第 6 染色体上的 RFLP 标记以及微卫星标记检 测 142 个已鉴定育性表现的 $F_{2}$ 植株的 DNA. 再利用 MAPMAKER 软件以 $\mathrm{LOD}=3.0$ 进行作图分析, 构建第 6 染色体的部分遗传连 锁图. 图 2 显示了温敏显性核不育基因在第 6 染色体的相对位 置, 它位于 RM50 和 C235 之间, 距微卫星标记 RM50 12. 9cM, RFLP 探针 C235 6. 4cM. 由于该基因是首次定位, 暂定名为 TMS.

\section{3 讨论}

迄今为止, 世界上仅在 10 种作物上发现了 15 例显性核不育 材料, 在水稻、小麦、油菜棉花和莴苣上各报道 2 例, 在谷子、大白 菜、马铃薯、亚麻和红胡麻草上各 1 例 ${ }^{[1]}$ 。按已报道显性核不育 基因的遗传方式, 分为 3 类: ( ) 不受环境条件影响的单基因控制 的显性核不育, 如小麦中报道的 $M S_{2}$ 和 $M S_{3}{ }^{[1,14]}$; ( ) 由单基因控 制在一定温度条件表现不育的温敏显性核不育, 如本研究报道的显 性核不育材料, 其育性在 $24^{\circ} \mathrm{C}$ 以下完全败育, $24 \sim 27^{\circ} \mathrm{C}$ 育性波动, $27^{\circ} \mathrm{C}$ 以上恢复可育; ( ) 基因互作型显性核不育, 育性由显性不育 基因和恢复其育性的显性上位性基因共同控制, 当二者同时存在的 时候表现正常可育, 显性不育基因单独存在时则表现雄性不育, 如 水稻萍乡核不育, 以及谷子和油菜中发现的核不育类型 $[3,15]$.

至于显性核不育基因的定位, 小麦的 2 个显性核不育基因 $M S_{2}$ (太谷核不育小麦) 和 $M S_{3}$ ( 远缘杂交人工诱导产生) 已分别定 位于 $4 \mathrm{D}$ 和 $5 \mathrm{~A}$ 染色体短臂 ${ }^{[1,14]}$. 本研究以 $\mathrm{F}_{2}$ 群体 $(8987 \times$ 地谷) 为基础, 采用 RFLP 和微卫星标记结合群分法, 将来源于 8987 的 水稻温敏显性核不育基因 TMS 定位于第 6 染色体. 在经典连锁

图 1 微卫星标记 RM50 在亲 本和不育基因近等池的多态性

1 —分子量标记, 2 - 8987 ,

3 - 地谷, 4 一不育基因池, 5 一一可育基因池

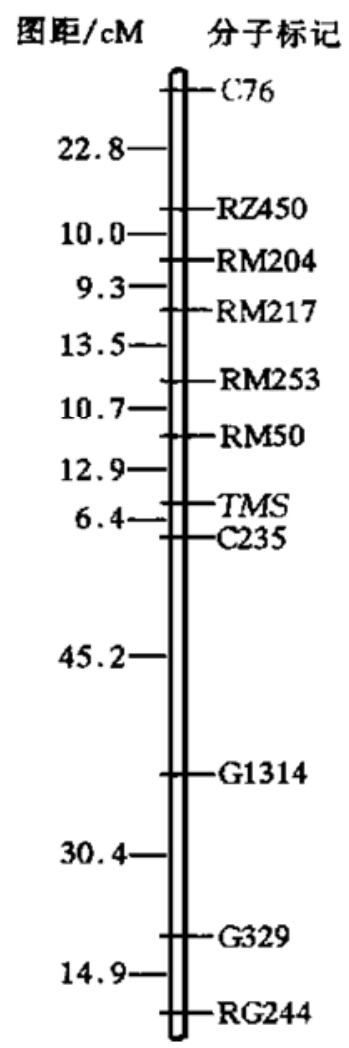

图 2 温敏不育基因 TMS 在第 6 染色体上的定位 图谱和分子图谱第 6 染色体相应区域还定位了水稻隐性核不育基因 $m s-1$ 和 $m s^{-9}$ 以及与育性 
有关的基因 $S n-5^{[4,16]}$. 至于这些控制水稻育性的基因是否与 $T M S$ 等位, 还有待于进一步研究.

\section{参 考 文 献}

1 刘秉华. 作物显性核不育基因的分类起源及在杂种生产中利用的可能性. 作物杂志, 1991，3: 26 28

2 Virmani S S. Heterosis and Hybrid Rice Breeding. Berlin: Springer-Verlag, 1994

3 颜龙安. 水稻显性核不育的初步研究. 作物学报. 1989. 15: 174 181

4 Khush G S, Kinoshita T. Rice karyotype, marker genes, and linkage groups. In: Kush G S, Toenniesen G H eds. Rice Biotechnology. Wallingford: CAB International, 1991, 83 108

5 张端品, 邓训安, 余功新, 等. 农剭 $58 \mathrm{~S}$ 光敏感雄性不育基因的染色体定位. 见: 袁隆平主编. 两系法杂交水稻研究论文 集. 北京: 中国农业出版社，1992.92 103

6 Zhang Q F, Shen P. An RFLP based genetic analysis of photoperiod sensitive male sterility in rice. Rice Genet Newslett, 1993, 10: 94 97

7 王斌, 王京兆, 金德敏, 等. 水稻温敏核不育基因的研究. 见: 863 计划两系杂交水稻专题研讨会監 1996 年海南年会论文 汇编, 1994. 132 134

8 邓晓建, 周开达. 低温敏显性核不育水稻“8987”的育性转换与遗传研究. 四川农业大学学报, 1994, 12 (3) : 376 382

9 Michelmore R W, Paran I, Kesseli R V. Identification of markers linked to disease 12 resistance genes by bulked segregation analysis: arapid method to detect markers in specific regions by using segregating populations. Proc Natl Acad Sci USA, 1991, 88: $9823 \sim 9832$

10 McCouch S R, Kochert G, Yu Z H. Molecular mapping of rice chromosomes. Theor Appl Genet, 1988, 76: 148 159

11 Chen X, Themnykh S, Xu Y, et al. Development of microsatellite framework providing genome-wide coverage in rice (Oryzae sativa L. ). Theor Appl Genet, 1997, 95(4) : 553 567

12 Panaud O, Chen X, McCouch S R. Development of microsatellite markers and characterization of simple sequence length polymorphisms (SSLPs) in rice (Oryza Sativa L.) . Mol Gen Genet, 1996, 252: 597 607

13 Lander E S, Green P, Abrahamson J, et al. MAPMAKER: an interactive computer for constructing primary genetics linkage maps of experimental and natural populations. Genomics, 1987, 1: 174 182

14 Sasakuma J, Maan S S. EMS induced male sterile mutants in euplasmic and alloplasmic common wheat. Crop Science, 1978, 18: 850 853

15 刘定富. 植物显性核不育恢复性遗传的理论探讨。遗传, 1992, 14: 31 36

16 Yanagihara S, McCouch S R, Ishikawa K, et al. Molecular analysis of the inheritance of the S-5 locus, conferring wide compatibility in indica/ japonica hybrids of rice (O. sativa L. ). Theor Appl Genet, 1995, 90: 182 188

(1998-09-07 收稿, 1998-11-26 收修改稿)

\section{肌肉电针介导 VEGF 基因治疗大鼠闭塞性血管病}

鲁东成 叶正茂 田学军 陈光慧 汤 健 朱国英 周爱儒 ( 北京医科大学心血管研究所. 北京 100083 )

摘要 应用电针介导血管内皮生长因子(VEGF) 基因治疗实验性外周血管闭塞症大鼠, 以 RTPCR 及免疫组化方法观察 VEGF 基因的表达, 通过血管造影技术观察 VEGF 基因导入大鼠体内 后的生物效应。结果显示, 电针介导 VEGF 基因可在大鼠肌肉组织高效表达 VEGF, 并可促进 局部组织新生血管形成和侧枝循环建立, 使血流恢复, 为闭塞性血管病的基因治疗提供一种新 的基因转移方法.

\section{关键词 电针介导基因转移 血管内皮生长因子 闭塞性血管病}

外周动脉闭塞性血管病是一类严重威胁人类健康的疾患, 目前尚无有效的治疗方法, 主要 